\title{
Experimental and Numerical Investigation on the Flow Characteristics around a Cross-Flow Wind Turbine
}

\author{
Takaaki Kono ${ }^{*}$, Akira Yamagishi' ${ }^{2}$, Takahiro Kiwata1, Shigeo Kimura², \\ Nobuyoshi Komatsu' ${ }^{2}$ \\ ${ }^{1}$ Research Center for Sustainable Energy \& Technology, Kanazawa University, Kanazawa, Japan \\ ${ }^{2}$ Division of Mechanical Science and Engineering, Kanazawa University, Kanazawa, Japan \\ Email: "t-kono@se.kanazawa-u.ac.jp
}

Received 18 February 2016; accepted 5 April 2016; published 8 April 2016

Copyright (C) 2016 by authors and Scientific Research Publishing Inc.

This work is licensed under the Creative Commons Attribution International License (CC BY).

http://creativecommons.org/licenses/by/4.0/

(c) () Open Access

\begin{abstract}
This study investigated the flow characteristics around a cross-flow wind turbine. A wind tunnel experiment (WTE) was performed to measure the flow characteristics past the wind turbine when operating at the optimal tip-speed ratio of $\lambda=0.4$. In addition, computational fluid dynamics (CFD) simulations were performed for the flow field around the wind turbine that was operating at tip-speed ratios of $\lambda=0.1,0.4$, and 0.7 . The CFD approach was validated against the WTE measurements. CFD results confirmed that with an increase in $\lambda$, the velocity deficit was generally increased in the leeward of the return side of the wind turbine, while it was generally decreased in the leeward of the drive side of the wind turbine. It was also confirmed that with an increase in $\lambda$, the turbulence kinetic energy was generally increased in the leeward of the return side of the wind turbine, while it generally decreased in the leeward of the drive side of the wind turbine.
\end{abstract}

\section{Keywords}

Cross-Flow Wind Turbine, Wind Tunnel Experiment, CFD

\section{Introduction}

A small wind turbine with a cross-flow runner (hereafter referred to as "cross-flow wind turbine") has a high starting torque and is quiet. Thus, it is suitable for it to be introduced in urban areas where wind speed is generally low and careful attention to noise reduction is required. However, it has a drawback in that its maximum

"Corresponding author.

How to cite this paper: Kono, T., Yamagishi, A., Kiwata, T., Kimura, S. and Komatsu, N. (2016) Experimental and Numerical Investigation on the Flow Characteristics around a Cross-Flow Wind Turbine. Energy and Power Engineering, 8, 173-182. http://dx.doi.org/10.4236/epe.2016.84016 
power coefficient is extremely low (about 10\%) when compared with that of other small wind turbines. To date, several studies have addressed ways to improve the efficiency of cross-flow wind turbines [1]-[4]. However, knowledge of flow characteristics around a cross-flow wind turbine is extremely limited. Therefore, there is great potential to improve cross-flow wind turbine's efficiency by taking flow characteristics into account.

In this study, we conduct computational fluid dynamics (CFD) simulations and a wind tunnel experiment (WTE) to clarify the flow characteristics around a cross-flow wind turbine.

\section{Experimental Method}

Figure 1 shows the schematic of the experimental setup. The experiment was conducted using a closed circuit wind tunnel with an open test section. The size of the cross section of the wind tunnel outlet was $1250 \mathrm{~mm} \times$ $1250 \mathrm{~mm}$.

The cross-flow wind turbine being tested, which is shown in Figure 2, had an outer diameter of $D=80 \mathrm{~mm}$, an inner diameter of $d=65 \mathrm{~mm}$, and a lateral length of $L=400 \mathrm{~mm}$. The shape of the blades was an arc of a circle with radius of $r=11.5 \mathrm{~mm}$, angle of $\theta=114^{\circ}$, and chord length of $l_{c}=10.5 \mathrm{~mm}$. The inlet angle of the blades was $\beta=40^{\circ}$, and the number of the blades was $N=15$.

The wind turbine was placed at $800 \mathrm{~mm}$ downwind from the wind tunnel outlet and $525 \mathrm{~mm}$ above the floor. The wind turbine then was connected to a torque meter and a direct current motor that controls the wind turbine's number of rotations.

The free stream velocity was set to $U=7 \mathrm{~m} / \mathrm{s}$, and the turbulence intensity was less than $0.5 \%$. Assuming that the origin lay at the center of the wind turbine, wind velocity distribution was measured using an $\mathrm{X}$-array hotwire probe (KANOMAX, 0252R-T5) at $z / D=0$ in the lateral direction, at the range of $x / D=-0.5$ to 2.0 in the streamwise direction, and at the range of $y / D=-1.5$ to 1.5 in the vertical direction, as shown in Figure 3 . The spacing of the measurement points was $5 \mathrm{~mm}$ in both the $x$ and $y$ directions.

\section{Numerical Analysis Method}

\subsection{Abbreviations and Acronyms}

Two-dimensional CFD simulation was performed for the flow field around the wind turbine on the $x-y$ plane at $z / D=0$. The governing equations are the Reynolds-averaged continuity equation

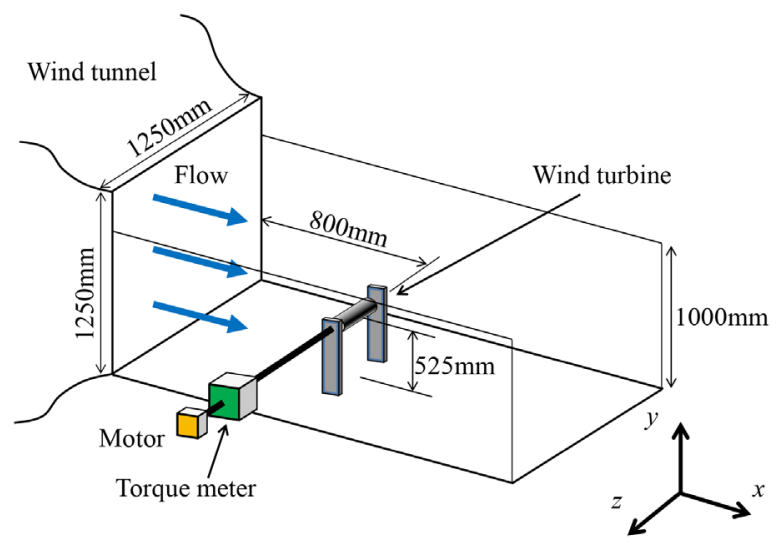

Figure 1. Experimental setup.
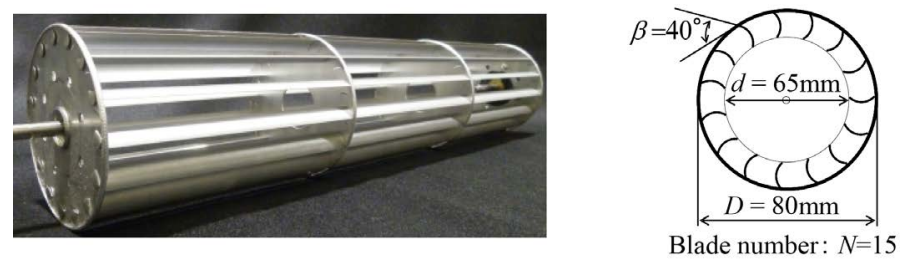

Figure 2. Cross-flow wind turbine. 


$$
\frac{\partial\left\langle u_{i}\right\rangle_{R}}{\partial x_{i}}=0
$$

and the Reynolds-averaged Navier-Stokes (RANS) equations

$$
\frac{\partial\left\langle u_{i}\right\rangle_{R}}{\partial t}+\frac{\partial\left\langle u_{i}\right\rangle_{R}\left\langle u_{j}\right\rangle_{R}}{\partial x_{j}}=-\frac{1}{\rho} \frac{\partial\langle p\rangle_{R}}{\partial x_{i}}+v \frac{\partial^{2}\left\langle u_{i}\right\rangle_{R}}{\partial x_{j}^{2}}-\frac{\partial}{\partial x_{j}}\left\langle u_{i}^{\prime \prime} u_{j}^{\prime \prime}\right\rangle_{R}
$$

where $u_{i}$ is the velocity component in the $x_{i}$ direction, $t$ is the time, $\rho$ is the density of air, $p$ is the pressure, $v$ is the kinetic viscosity, and $\langle\phi\rangle_{R}$ is the Reynolds-average of a flow variable $\phi$. The Reynolds stresses $\left\langle u_{i}^{\prime \prime} u_{j}^{\prime \prime}\right\rangle_{R}$ were computed using the $k-\omega$ shear-stress transport (SST) turbulence model [5]. The advection term was discretized by the second-order upwind scheme. Other spatial derivatives were discretized via the second-order central difference scheme. The Pressure-Implicit with Splitting of Operators (PISO) algorithm was used for velocitypressure coupling.

\subsection{Computational Conditions}

The detail of the computational grid is shown in Figure 4. The computational domain consists of a rotational area, which includes the wind turbine, and a stationary area that surrounds it. A sliding mesh technique was used

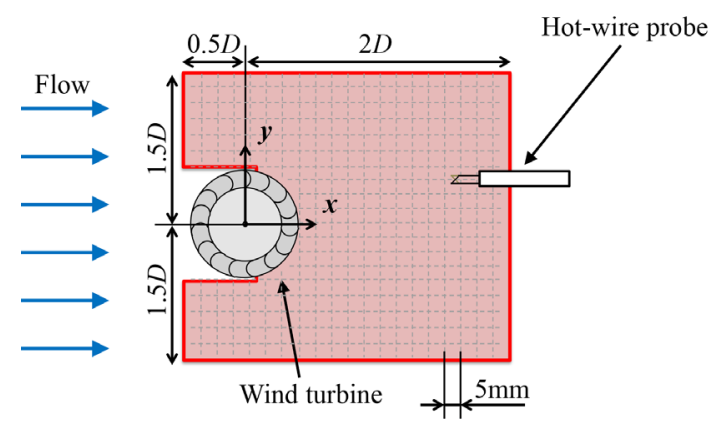

Figure 3. Measurement range.

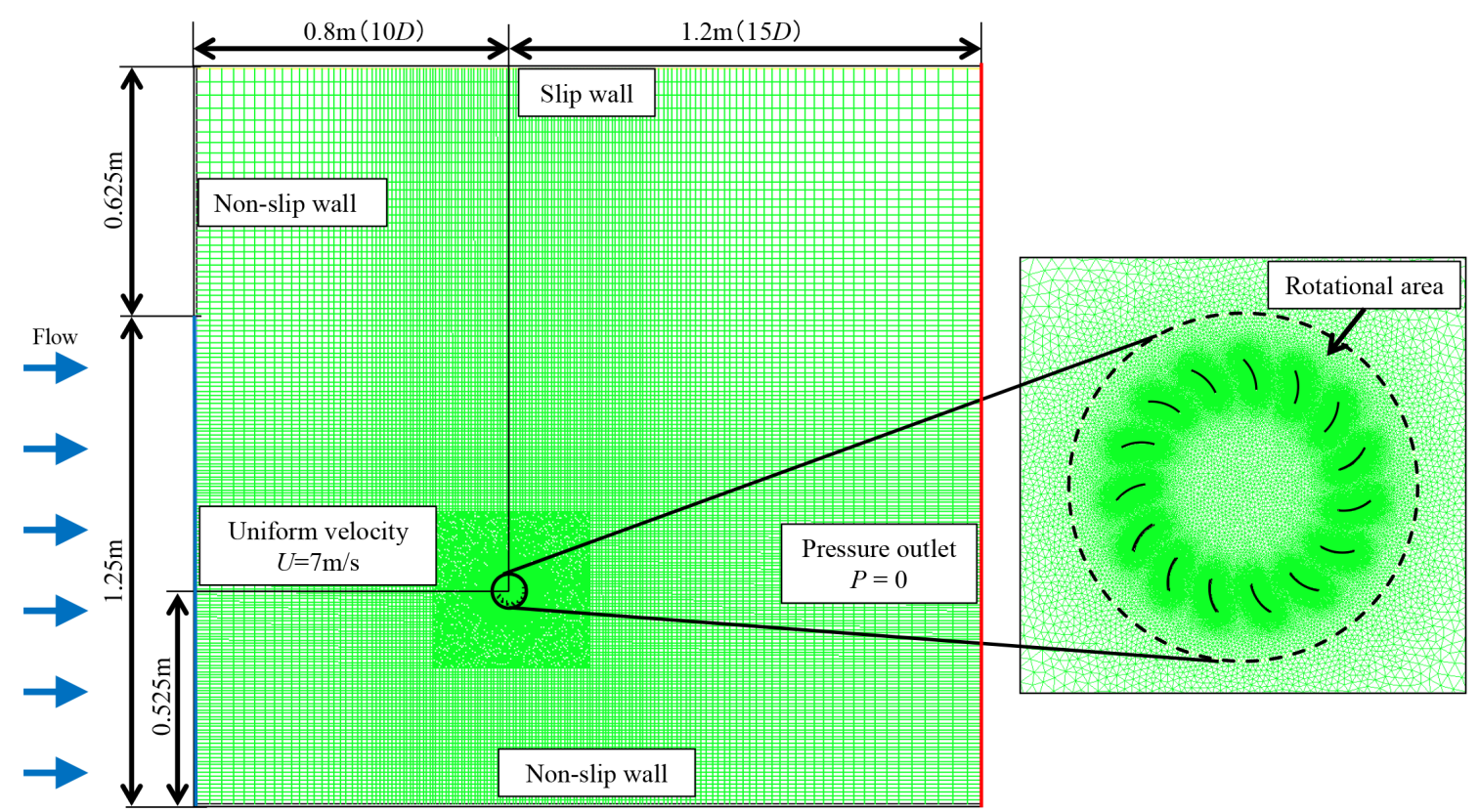

(a)

(b)

Figure 4. Computational grid. (a) Entire domain, (b) enlarged view. 
to couple the rotational grid and stationary grid, as described in literature [6]. The total number of grid points was approximately 250,000.

On the inflow boundary, a stream-wise wind speed of $U=7 \mathrm{~m} / \mathrm{s}$ with the turbulent intensity of $0.5 \%$ was implemented. On the outlet boundary, the pressure outlet boundary condition was imposed. On the bottom boundary of the computational domain and blade surface, the non-slip boundary condition was set. On the top boundary of the computational domain, the free-slip boundary condition was implemented.

The tip-speed ratio $\lambda(=D \omega / U)$ of the wind turbine was set with $U$ being constant and $\omega$, the turbine's angular velocity, being changed. The time step $\Delta t(=\pi / 360 \omega)$ is the period of time for the wind turbine to rotate by 0.5 degrees. The statics were summed up from $3600 \Delta t$ to $7200 \Delta t$.

\section{Results and Discussion}

\subsection{Power Coefficient}

Figure 5 shows the dependence of the power coefficient $C_{P}\left(=2 T \omega / L D \rho U^{3}\right)$ on the tip-speed ratio $\lambda$, where $T$ is the turbine's torque. It is observed that the CFD results match well.

\subsection{Flow Characteristics around Wind Turbine at Optimal Tip-Speed Ratio}

In this section, we focus on the flow characteristics around the wind turbine when operating at $\lambda=0.4$.

Figure 6 shows the time-averaged velocity profiles of the flow past the wind turbine. The profiles of the CFD and WTE results appear to be in good agreement except for the streamwise velocities in the range of $y / D=-0.5$ to 0.0 . The large discrepancies between the CFD and WTE results for the streamwise velocity likely due to the difference in the generation frequency of the strong counter-clockwise vortices, one of which is indicated by the dashed oval in Figure 7, shed from the return side of the wind turbine. Based on Figure 8, which shows the

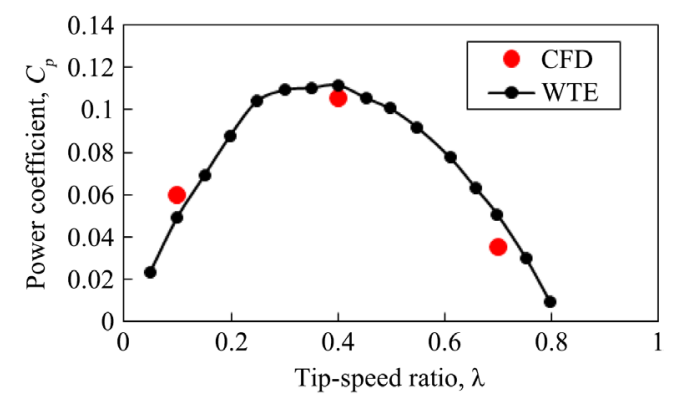

Figure 5. Dependence of the power coefficient $C_{P}$ on the tip-speed ratio $\lambda$.

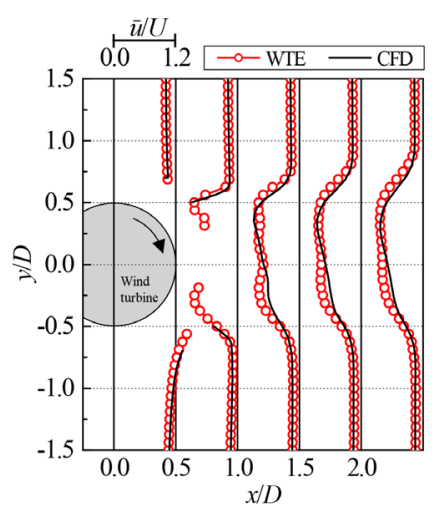

(a)

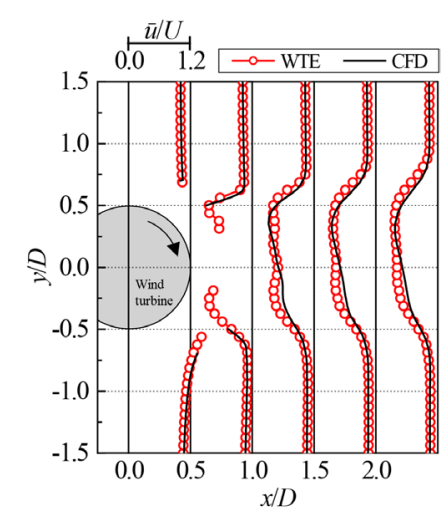

(b)

Figure 6. Time-averaged velocity profiles of the flow past the wind turbine when operating at $\lambda=0.4$. (a) Streamwise velocity, (b) vertical velocity. 

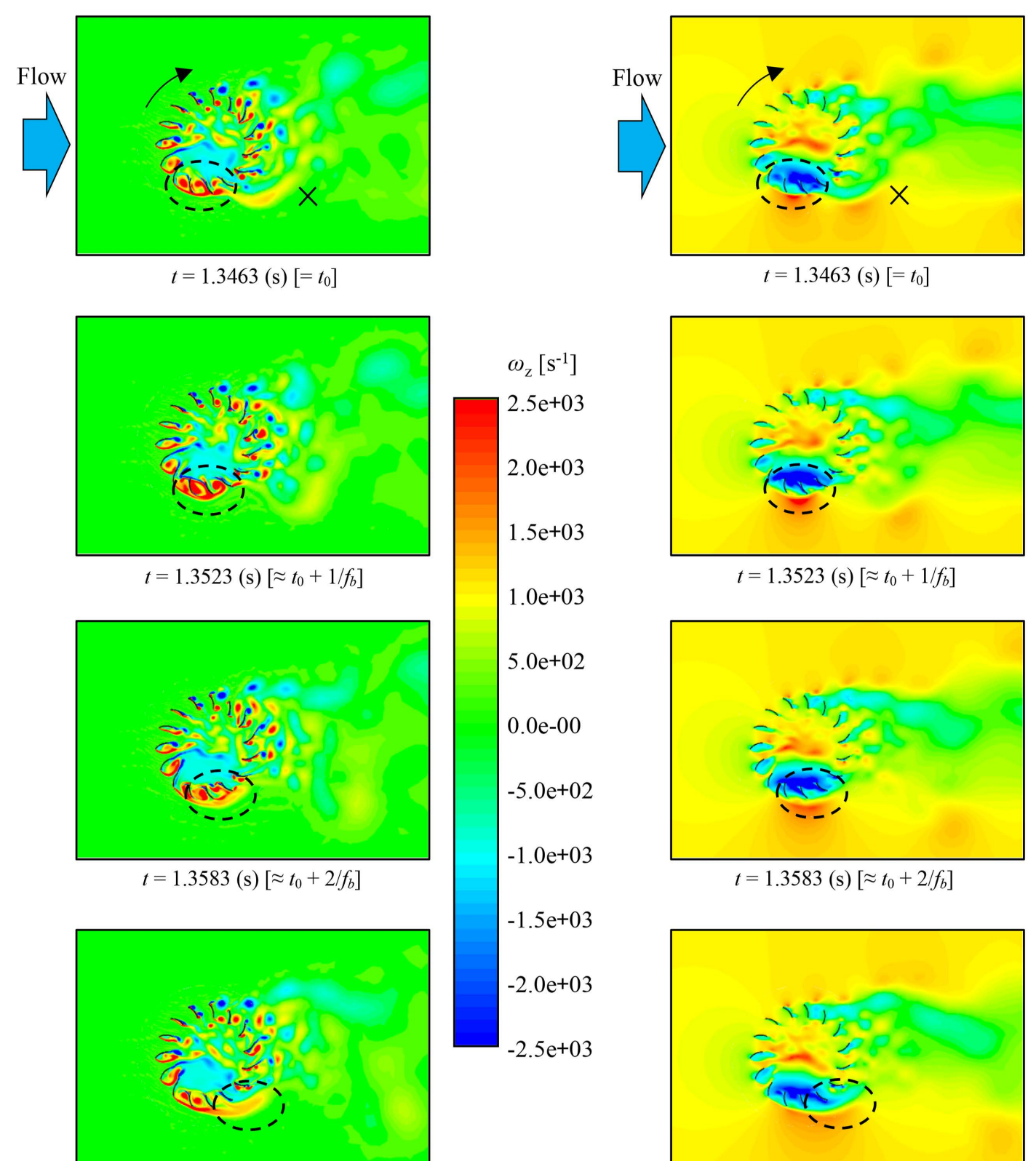

$t=1.3583(\mathrm{~s})\left[\approx t_{0}+2 / f_{b}\right]$

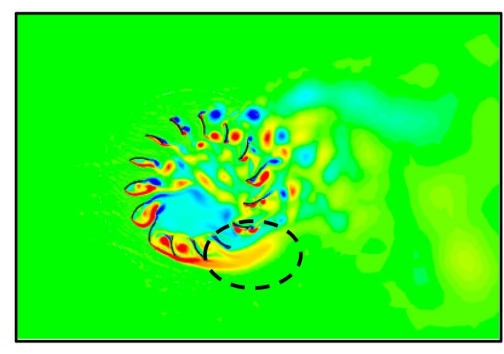

$t=1.3643(\mathrm{~s})\left[\approx t_{0}+3 / f_{b}\right]$

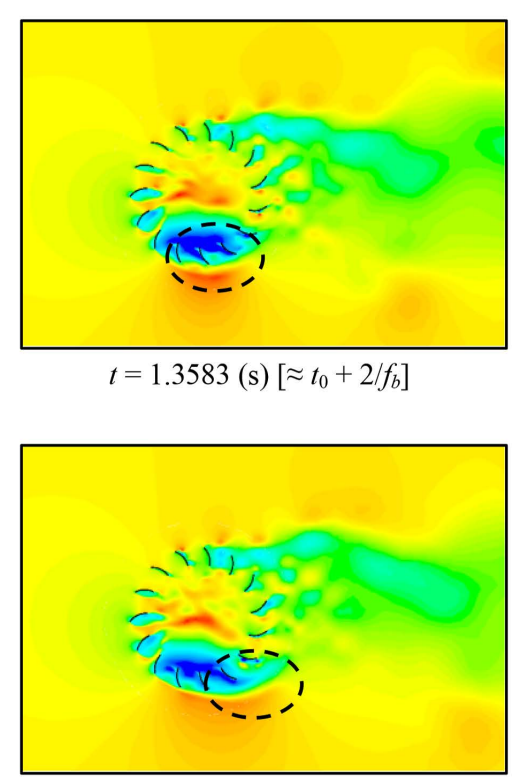

$u[\mathrm{~m} / \mathrm{s}]$

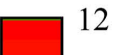

10

8.0

6.0

4.0

2.0

0.0

$t=1.3643(\mathrm{~s})\left[\approx t_{0}+3 / f_{b}\right]$

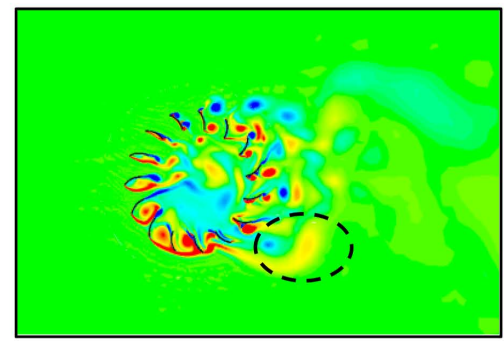

$t=1.3702(\mathrm{~s})\left[\approx t_{0}+4 / f_{b}\right]$

(a)

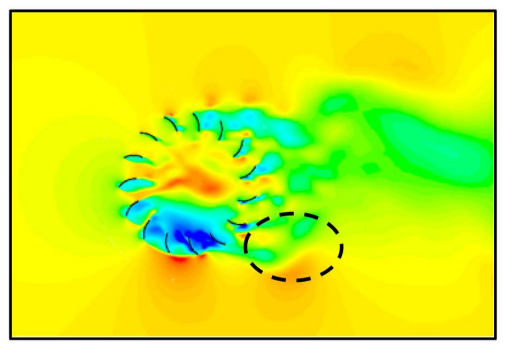

$t=1.3702(\mathrm{~s})\left[\approx t_{0}+4 / f_{b}\right]$

(b)

Figure 7. Contours of axial vorticity and streamwise velocity around the wind turbine when operating at $\lambda=0.4$. (a) Axial vorticity, (b) streamwise velocity. 
frequency spectra of the streamwise velocity fluctuations at the position indicated by a cross mark in Figure 7 (a), the strong counter-clockwise vortices are periodically shed from the return side of the wind turbine at a frequency of approximately $f_{b} / 4 \mathrm{~Hz}$ in CFD and $f_{b} / 3 \mathrm{~Hz}$ in WTE. Here, $f_{b}$ is the blade passing frequency (the product of the rotor rotation frequency and the number of blades) shown in Table 1.

Figure 9 shows the turbulence kinetic energy (TKE) profiles of the flow past the wind turbine. Here, the values of TKE of WTE are calculated by

$$
\mathrm{TKE}_{\mathrm{WTE}}=\frac{1}{2}\left(\overline{u^{\prime 2}}+\overline{v^{\prime 2}}+\overline{w^{\prime 2}}\right),
$$

and the values of TKE of CFD are calculated using the following approximate equations, (see Appendix):

$$
\mathrm{TKE}_{\mathrm{CFD}}=\frac{1}{2}\left(\overline{u^{\prime \prime \prime 2}}+\overline{v^{\prime \prime 2}}+\overline{w^{\prime \prime \prime 2}}\right)+\bar{k},
$$

where $\bar{\phi}$ is the time average of a flow variable $\phi, \phi^{\prime}$ is $\phi-\bar{\phi}, \phi^{\prime \prime \prime}$ is $\phi^{\prime}-\phi^{\prime \prime}$, and $k$ is the TKE of the SST $k$ - $\omega$ turbulence model. Figure 9 confirms that the profiles of the WTE and CFD results match qualitatively well, having two peaks around $y / D \approx-0.5$ and $y / D \approx 0.5$ to 0.9 . It is considered that these two peaks were generated by the vortices released from the wind turbine, as shown in Figure 7(a).

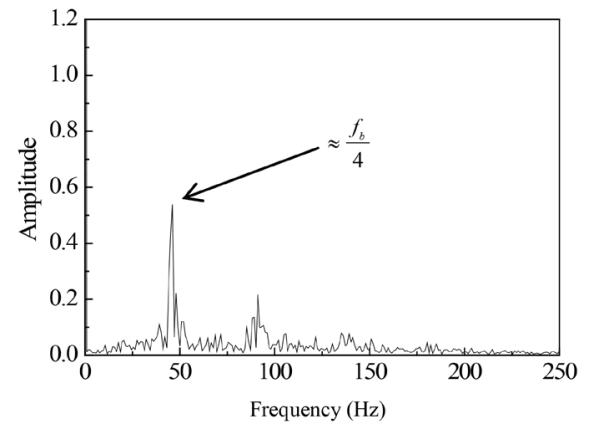

(a)

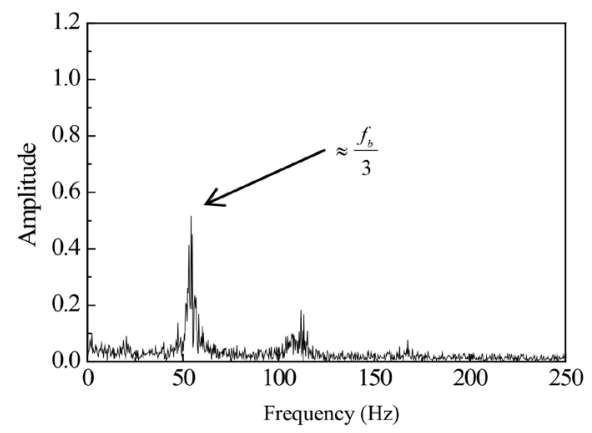

(b)

Figure 8. Frequency spectra of the streamwise velocity fluctuations at the position indicated by a cross mark in Figure 7(b). (a) CFD, (b) WTE.

Table 1. Blade passing frequency.

\begin{tabular}{cccc}
\hline Tip speed ratio, $\lambda$ & 0.1 & 0.4 & 0.7 \\
\hline Blade pasing frequency, $f_{b}(\mathrm{~Hz})$ & 41.5 & 167.25 & 291.75 \\
\hline
\end{tabular}

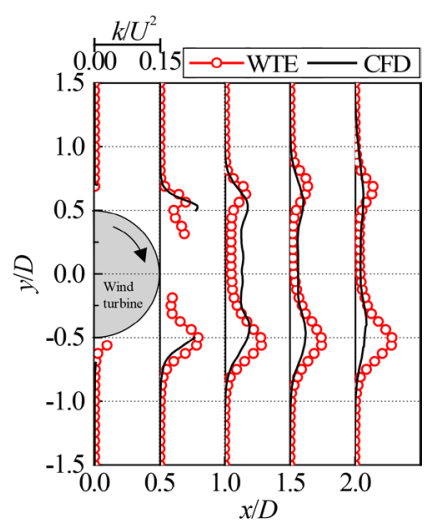

Figure 9. Turbulence kinetic energy profiles of the flow past the wind turbine when operating at $\lambda=0.4$. 


\subsection{Dependency of Flow Characteristics on the Tip-Speed Ratio of the Wind Turbine}

In this section, based on the CFD results, we discuss the dependency of the flow characteristics on the tip-speed ratio of the wind turbine.

Figure 10(a) compares the time-averaged streamwise velocity profiles of the flow past the wind turbine when operating at various tip-speed ratios. With an increase in $\lambda$, the velocity deficit is generally increased in the leeward of the return side of the wind turbine $(y / D<0)$, and in the leeward of the drive side of the wind turbine $(y / D>0)$, the velocity deficit is generally decreased.

Figure 10(b) compares the TKE profiles of the flow past the wind turbine when operating at various tip-speed ratios. With an increase in $\lambda$, the values of TKE are generally increased in the leeward of the return side of the wind turbine, and in the leeward of the drive side of the wind turbine, the values of TKE are generally decreased.

With regard to the causes of the dependencies of the velocity deficit and TKE on $\lambda$, the characteristics of the vortices shed from the drive side and from the return side of the wind turbine vary depending on $\lambda$. Figure 11 shows the contours of the axial vorticity around the wind turbine at $\lambda=0.1$ and 0.7 , respectively. According to Figure 7(a) and Figure 11, the vortices shed from the return side of the wind turbine become larger and stronger as $\lambda$ increases. As a result, the velocity deficit and TKE in the leeward of the return side increases with an increase in $\lambda$. The formation of larger and stronger vortices with an increase in $\lambda$ is considered to stem from the fact that the shear stress near the blades on the return side of the wind turbine increases due to an increase in the speed of the blades that move in the opposite direction of the flow around the wind turbine. Moreover, based on Figure 7(a) and Figure 11, the vortices shed from the drive side of the wind turbine become smaller and weaker as $\lambda$ increases. As a result, the velocity deficit and TKE in the leeward of the drive side decreases with an increase in $\lambda$. The formation of smaller and weaker vortices with an increase in $\lambda$ is considered to occur because the interaction between the opposite sign of the vortices from the edges of a blade becomes less frequent due to an increase in the frequency of the reattachment of the vortices from the inner edge of a blade.

\section{Conclusions}

To clarify the flow characteristics around a cross-flow wind turbine, a wind tunnel experiment (WTE) and computational fluid dynamics (CFD) simulations were conducted. The CFD simulations were performed for the cases in which the wind turbine was operating at tip-speed ratios of $\lambda=0.1,0.4$, and 0.7 . The validity of the CFD approach was confirmed through the comparison with the WTE results for the optimal tip-speed ratio of $\lambda=0.4$. The main findings are summarized as follows.

1) With an increase in $\lambda$, the velocity deficit is generally increased in the leeward of the return side of the wind turbine, while it is generally decreased in the leeward of the drive side of the wind turbine.

2) With an increase in $\lambda$, the turbulence kinetic energy is generally increased in the leeward of the return side of the wind turbine, while it is generally decreased in the leeward of the drive side of the wind turbine.

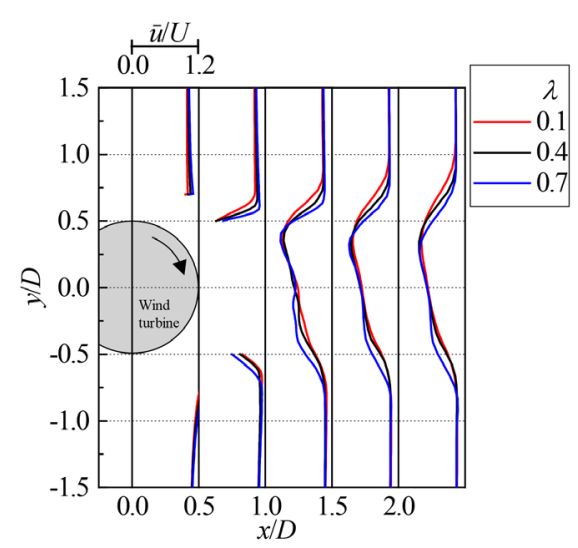

(a)

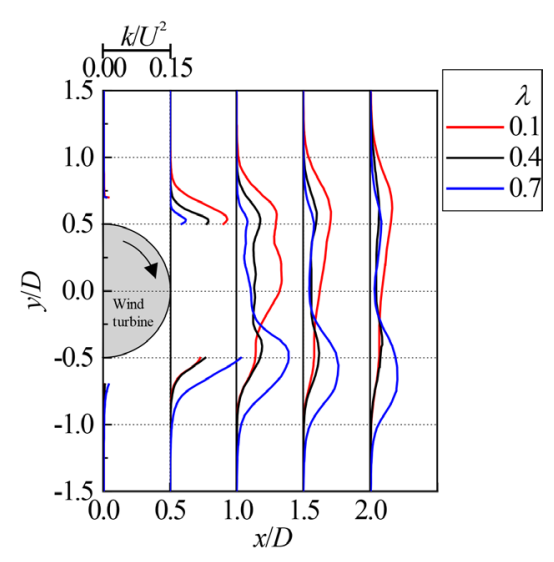

(b)

Figure 10. Time-averaged streamwise velocity and turbulence kinetic energy profiles of the flow past the wind turbine. (a) Streamwise velocity, (b) turbulence kinetic energy. 


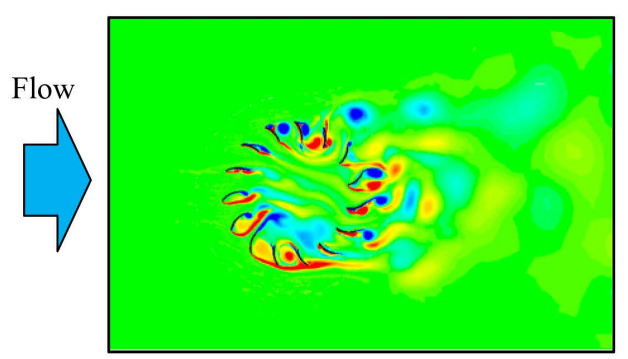

$t=5.4226$ (s)

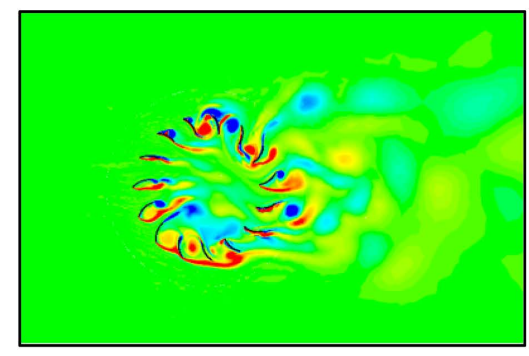

$t=5.4286(\mathrm{~s})$

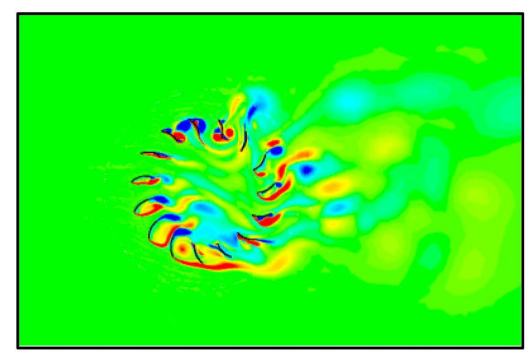

$t=5.4346$ (s)

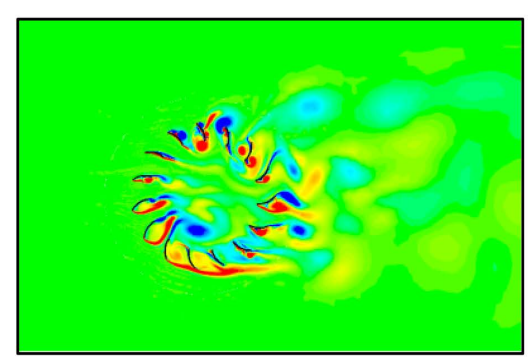

$t=5.4407$ (s)

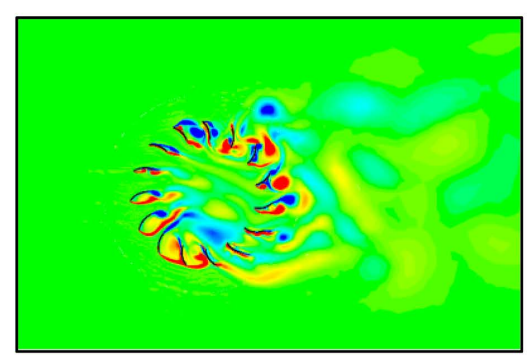

$t=5.4467$ (s)

(a)

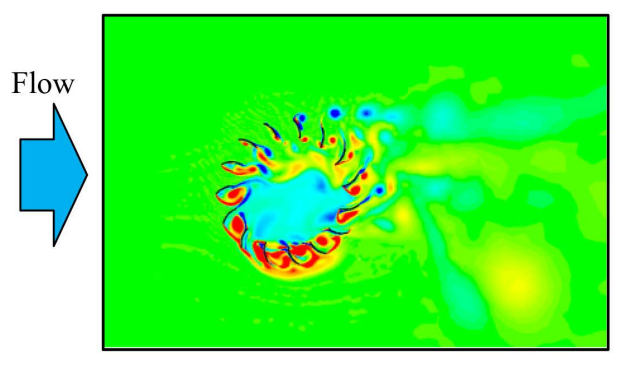

$t=0.77187$ (s)

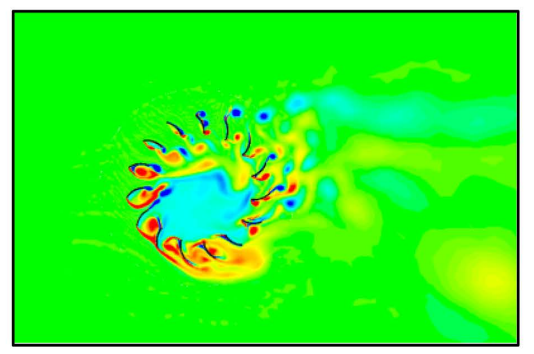

$t=0.77787$ (s)

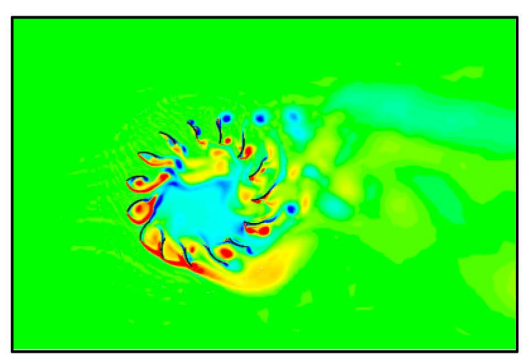

$t=0.78387$ (s)

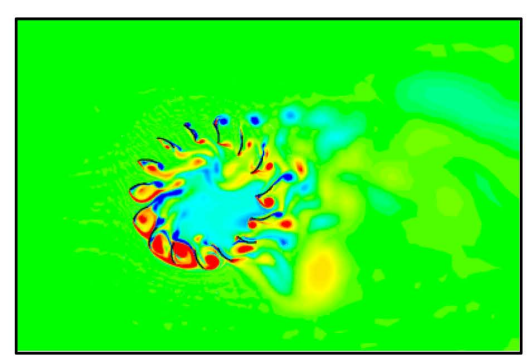

$t=0.78987$ (s)

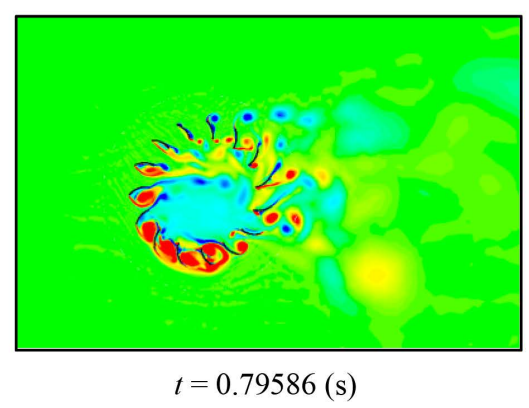

(b)

Figure 11. Contours of axial vorticity around the wind turbine when operating at $\lambda=0.1$ and 0.7 . (a) $\lambda=0.1$, (b) $\lambda=0.7$. 
3) With an increase in $\lambda$, the vortices shed from the return side of the wind turbine tend to be larger and stronger.

4) With an increase in $\lambda$, the vortices shed from the drive side of the wind turbine tend to be smaller and weaker.

\section{References}

[1] Al-Maaitah, A.A. (1993) The Design of the Banki Wind Turbine and Its Testing in Real Wind Conditions. Renewable Energy, 3, 781-786. http://dx.doi.org/10.1016/0960-1481(93)90085-U

[2] Tanino, T. and Nakao, S. (2005) Improving Ambient Wind Environments of a Cross-Flow Wind Turbine near a Structure by Using an Inlet Guide Structure and a Flow Deflector. Journal of Thermal Science, 14, 242-248. http://dx.doi.org/10.1007/s11630-005-0008-0

[3] Shigemitsu, T., Fukutomi, J. and Takeyama, Y. (2009) Study on Performance Improvement of Cross-Flow Wind Turbine with Symmetrical Casing. Journal of Environment and Engineering, 4, 490-501. http://dx.doi.org/10.1299/jee.4.490

[4] Dragomirescu, A. (2011) Performance Assessment of a Small Wind Turbine with Crossflow Runner by Numerical Simulations. Renewable Energy, 36, 957-965. http://dx.doi.org/10.1016/j.renene.2010.07.028

[5] Menter, F.R., Langtry, R.B., Likki, S.R., Suzen, Y.B., Huang, P.G. and Volker, S. (2006) A Correlation-Based Transition Model Using Local Variables_-Part I: Model Formulation. Journal of Turbomachinery, 128, 413-422. http://dx.doi.org/doi:10.1115/1.2184352

[6] ANSYS Inc. (2009) Fluent 12.0 User's Guide. 


\section{Appendix}

The approximate Equation (4) is derived as follows.

With time averaging and Reynolds averaging, an instantaneous velocity is decomposed as

$$
\begin{gathered}
u_{i}=\bar{u}_{i}+u_{i}^{\prime}, \\
u_{i}=\left\langle u_{i}\right\rangle_{R}+u_{i}^{\prime \prime}=\bar{u}_{i}+u_{i}^{\prime \prime \prime}+u_{i}^{\prime \prime},
\end{gathered}
$$

The turbulence kinetic energy based on time-averaging operation is defined as

$$
\mathrm{TKE}=\frac{1}{2}\left(\overline{u^{\prime 2}}+\overline{v^{\prime 2}}+\overline{w^{\prime 2}}\right),
$$

Using the relationship in Equation (A.2), Equation (A.3) is expressed as

$$
\mathrm{TKE}=\frac{1}{2}\left(\overline{\left(u^{\prime \prime}+u^{\prime \prime \prime}\right)^{2}}+\overline{\left(v^{\prime \prime}+v^{\prime \prime \prime}\right)^{2}}+\overline{\left(w^{\prime \prime}+w^{\prime \prime \prime}\right)^{2}}\right),
$$

Because using the present CFD approach is not possible for computing the values of $w^{\prime 2}$ and $\overline{u_{i}^{\prime \prime} u_{j}^{\prime \prime \prime}}$ in Equation (A.4), the present study assumes these values to be zero. As a result, Equation (4) is obtained. 